\title{
PENENTUAN NILAI SUN PROTECTION FACTOR SECARA IN VITRO PADA EKSTRAK ETANOL AKAR KALAKAI (Stenochlaena palustris Bedd) DENGAN METODE SPEKTROFOTOMETER UV-VIS
}

\author{
Rabiatul Adawiyah ${ }^{1}$ \\ 1'Dosen D III Farmasi, Fakultas IImu Kesehatan, Universitas Muhammadiyah \\ Palangkaraya, Palangka Raya, Kalimantan Tengah \\ e-mail : abi.ubiet@gmail.com
}

\begin{abstract}
ABSTRAK
Bahan yang mampu melindungi kulit dari paparan sinar ultraviolet (UV) disebut tabir surya atau Sun Protecting Agent.Nilai Sun Protectian Factor adalah menunjukkan berapa kali perlindungan kulit seseorang dilipatgandakan sehingga aman dibawah matahari tanpa mengalami eritema.Kalakai mengandung beberapa senyawa bioaktif seperti fenol, flavonoid, alkaloid dan keluarga terpenoid yang telah terbukti sangat efektif sebagai antioksidan.Tujuan penelitian ini adalah untuk menentukan konsentrasi ekstrak etanol akar kalakai yang memiliki potensi sebagai tabir surya berdasarkan parameter Sun Protection Factor (SPF). Penentuan nilai SPF dilakukan secara in vitrodengan spektrofotometer UV-VIS pada konsentrasi 50 ppm, 100 ppm, 150 ppm, 200 ppm, 250 ppm, 300 ppm, dan 350 ppm dengan panjang gelombang 290-320 nm blanko yang digunakan adalah etanol $70 \%$. Hasil menunjukkan bahwa ekstrak etanol akar kalakai menunjukkan potensi sebagai tabir surya pada konsentrasi 300 ppm dan 350 ppm diperoleh nilai SPF berturut-turut yaitu 11 dan 14 yang tergolong tabir surya dengan tingkat kemampuan ekstrim.
\end{abstract}

Kata Kunci : Akar Kalakai, Etanol, Spektorfotometer UV-VIS, dan Tabir Surya

\begin{abstract}
The sunscreens or Sun Protecting Agent is the materials protecting the skin from the exposure to ultraviolet (UV) rays. Amount of Sun Protection Factor shows how many times the subject skin protection can be multiplied under the sun rays without erythema occurs. Kalakai contains some bio-active substance like fenol, flavonoid, alkanoid and terpenoid family which are proven as a very effective antioxidant. The purpose of this research was to determine the concentration of ethanol extract of kalakai root which has the potential as a sunscreen based on the Sun Protectian Factor (SPF) parameter. Determination of SPF amount was carried out in vitro by UV-VIS spectrophotometer at a concentration of $50 \mathrm{ppm}$, 100 ppm, 150 ppm, 200 ppm, 250 ppm, 300 ppm, and 350 ppm with a wavelength of 290$320 \mathrm{~nm}$. The result showed that kalakai root ethanol extract indiccated potential as a sunscreen at a concentration of 300 ppm and 350 ppm obtained SPF values respectively 11 and 14 classified as sunscreens with extreme ability levels.
\end{abstract}

Keywords: Kalakai Root, Ethanol, UV-VIS Spectrophotometer, and Sunscreen Rays 


\section{PENDAHULUAN}

Matahari Memiliki efek menguntungkan dan berbahaya.Matahari sangat penting untuk kehidupan di Bumi karena berfungsi mendukung kehidupan melalui fotosintesis pada tanaman, dan dengan memberikan kehangatan dan cahaya.Selain itu, matahari sangat penting untuk kesejahteraan fisik dan fisiologis manusia ${ }^{1}$. Namun paparan sinar matahari berlebih dapat memberikan efek negatif pada kulit yang tidak terlindungi seperti kulit terbakar, terasa kasar, penuaan dini, hingga kanker kulit.Efek negatif tersebut yang disebabkan oleh sinar matahari yaitu sinar ultraviolet atau sinar UV.

Radiasi UV merupakan salah satu komponen utama yang dipancarkan oleh sinar matahari². Radiasi UV terdiri dari 2 tipe yaitu : UV-A dan UV-B, pada huruf $A$ pada UV-A berarti "Aging" (penuaan) dengan panjang gelombang 320-400 nm dapat menembus dermis yang menyebabkan pigmentasi. Sedangkan UV-B yang huruf B berarti "Burning" (pembakaran) dengan panjang gelombang 290-320 nm dan dapat menembus lapisan paling luar kulit (epidermis) yang efeknya dapat terlihat secara langsung berupa eritema.Paparan radiasi UV yang berlebihan dapat menyebabkan kerusakan kulit akibat adanya radikal bebas yang terbentuk, sehingga di perlukan suatu bahan untuk melindungi kulit dari paparan sinar UV.Bahan yang mampu melindungi kulit dari paparan sinar UV disebut tabir surya atau Sun Protecting Agent.Salah satu senyawa yang memiliki aktifitas sebagai tabir surya dari bahan alami yaitu golongan senyawa fenolik.Kemampuan suatu tabir surya dapat melindungi kulit dengan menunda eritema dinyatakan dengan Sun Protection Factor (SPF ${ }^{3}$.

Nilai SPF menunjukkan berapa kali perlindungan kulit seseorang dilipatgandakan sehingga aman di bawah matahari tanpa mengalami eritema, semakin tinggi nilai SPF suatu tabir surya, maka semakin baik pula aktivitas perlindungannya ${ }^{4}$. Pengukuran nilai SPF suatu sediaan tabir surya dapat dilakukan secara in vitro.Metode pengukuran nilai SPF secra in vitro secara umum terbagi dalam dua tipe. Tipe pertama adalah dengan cara mengukur serapan atau transmisi radiasi UV melalui lapisan produk tabir surya pada plat kuarsa atau biomembran. Tipe kedua dengan cara menentukan karakteristik searapan tabir surya menggunakan analisis secara spektrofotometri larutan hasil pengenceran dari tabir surya yang diuji ${ }^{5}$.

Salah satu tumbuhan Khas dari Kalimantan Tengah yang tumbuh subur di adalah Kalakai.Salah satu bagian tumbuhan kalakai yang berpotensi mempunyai aktivitas sebagai antioksidan adalah akar kalakai. Penelitian yang dilakukan oleh Adawiyah dan Rizki (2018), menyatakan bahwa aktivitas antioksidanekstrak etanol akar kalakai yang diuji menggunakan Parameter 
Inhibitory Concentration50 $\left(\mathrm{IC}_{50}\right)$ dengan metode DPPH (2,2- difenil-1-pikrilhidrazil) memilikiaktvitas yang sangat kuat menghasilkan nilai $\mathrm{IC}_{50}$ sebesar 19,06 PPM.Tujuan penelitian ini adalah untuk menentukan konsentrasi ekstrak etanol akar kalakai yang memiliki potensi sebagai tabir surya berdasarkan parameter Sun Protectian Factor (SPF).

\section{METODOLOGI}

Penelitian ini dilaksanakan di Laboratorium Fakultas IImu Kesehatan UM Palangka Raya dan FMIPA Universitas Lambung Mangkurat Banjarbaru. Sampel yang digunakan pada penelitian ini adalah akar kalakai (Stenochlaena palutrisBedd) yang berasal dari kota Palangka Raya, Kalimantan Tengah. Bahan yang digunakan adalah ekstrak etanol akar kalakai, etanol $70 \%$, aquadest. Alat yang digunakan alat-alat gelas kimia, mikropipet, kertas saring, timbangan analitik,rotary evaporator, waterbath, dan spektofotometer UV-Vis.

\section{Ekstraksi Akar Kalakai}

Akar dari tumbuhan kalakai yang telah dikumpulkan dan dikeringkan kemudian dihaluskan hingga menjadi serbuk kasar. Serbuk ditimbang masingmasing sebanyak $100 \mathrm{~g}$ kemudian diekstraksi dengan metode maserasi menggunakan pelarut etanol $70 \%$ dengan perbandingan 1:10 selama $3 \times 24$ dengan penggantian pelarut setiap 24 jam. Hasil yang diperoleh dari maserasi kemudian dipekatkan menggunakan rotary evaporator, kemudiandiuapkan di atas waterbath hingga terbentuk ekstrak kental ${ }^{6}$. Didapatlah ekstrak etanol dari akar kalakai.

\section{Penentuan Sun Protection Factor (SPF)}

Penentuan efektifitas tabir surya dilakukan dengan menentukan dari nilai SPF secara In Vitrodengan menggunakan spektrofotometer UV-Vis. Ekstrak akar kalakai yang akan digunakan diencerkan dibagi menjadi beberapa konsentrasi dan dibaca menggunakan spektrofotometer UV-Vis dengan panjang gelombang antara 290-320 nm setiap interval $5 \mathrm{~nm}$, blanko yang digunakan adalah etanol $70 \%$. Kemudian dihitung hasil absorbansinya untuk digunakan menghitung nilai SPF, dengan rumus sebagai berikut :

$\mathrm{SPF}=\mathrm{CF} x \sum_{290}^{320} \mathrm{EE}(\lambda) \mathrm{x} \mathrm{I}$

$(\lambda) \mathrm{x}$ absorbansi $(\lambda)$

Keterangan :

CF : Faktor Koreksi (10) EE : Efisiensi eriternal

Abs : Serapan tabir surya

I : Spektrum simulasi sinar surya

Konstanta EE $\times$ I dapat dilihat pada tabel 1 
Tabel 1. Nilai EE x I pada panjang gelombang $290-320 \mathrm{~nm}$

\begin{tabular}{cc}
\hline $\begin{array}{c}\text { Panjang } \\
\text { gelombang }(\lambda \\
\mathrm{nm})\end{array}$ & EE x I \\
\hline 290 & 0,0150 \\
295 & 0,0817 \\
300 & 0,2874 \\
305 & 0,3278 \\
310 & 0,1864 \\
315 & 0,0839 \\
320 & 0,0180 \\
\hline Total & 1 \\
\hline \multicolumn{2}{c}{ (Pratiwi et al., 2016) }
\end{tabular}

Tingkat kemampuan tabir surya dikelompokkan berdasarkan nilai indeks ultraviolet menurut ketentuan WHO dapat dilihat pada tabel 2 sebagai berikut:

Tabel 2. Tingkat kemampuan tabir surya berdasarkan nilai indeks ultraviolet

\begin{tabular}{cc}
\hline SPF & $\begin{array}{c}\text { Kategori Proteksi Tabir } \\
\text { Surya }\end{array}$ \\
\hline $1-2$ & Proteksi lemah \\
$3-4$ & Proteksi sedang \\
$8-10$ & Proteksi kuat \\
$\geq 11$ & Proteksi maksimal \\
\hline
\end{tabular}

Keterangan :

1-2 : Tidak ada perlindungan

3-7 : Perlindungan yang di

butuhkan

8- $\geq 11$ : Mempunyai perlindungan lebih/ekstra

(WHO, 2003)

\section{HASIL DAN PEMBAHASAN}

Sampel yang digunakan dalam penelitian ini adalah akar kalakai yang tumbuh di kota Palangka Raya Kalimantan Tengah. Sampel akar kalakai yang dikumpulkan diolah menjadi simplisia dan dibuat menjadi ekstrak menggunakan pelarut etanol $70 \%$ dengan metode maserasi. Digunakan penyari etanol $70 \%$ karena memiliki daya penetrasi yang baik dalam menembus dinding sel sampel untuk menarik senyawa aktif. Etanol $70 \%$ juga mampu menarik senyawa metabolit sekunder lebih baik dibandingkan etanol murni. Etanol juga tidak bersifat toksik dibanding metanol ${ }^{7}$. Setelah menjadi ekstrak dilakukan perhitungan rendemen. Rendemen ekstrak dihitung berdasarkan perbandingan berat ekstrak dengan berat awal dikalikan 100\%. Hasil rendemen ekstrak etanol yang diperoleh adalah $3,28 \%$.

$$
\text { Penelitian Adawiyah }
$$
tentang skrining fitokimia ekstrak etanol tumbuhan kalakai, yang digunakan pada akar kalakai didapat hasil organoleptis dengan mendeskripsikan bentuk, warna, bau, dan rasa dapat dilihat pada tabel 3 . Tujuannya yaitu pengenalan awal dari ekstrak yang dihasilkan secara sederhana. 
Tabel 3. Hasil Pengamatan Pembuatan

Ekstrak Akar Kalakai

\begin{tabular}{|l|l|}
\hline \multicolumn{1}{|c|}{ Nama Sampel } & \multicolumn{1}{|c|}{ Organoleptis Ekstrak } \\
\hline Ekstrak Etanol & Bentuk : ekstrak kering, \\
Akar Kalakai & Warna : kecoklatan, \\
& Bau : khas, \\
& Rasa: pahit \\
\hline
\end{tabular}

\section{Nilai SPF Ekstrak Akar Kalakai}

Penetuan nilai SPF pada penelitian ini adalah sebagai parameter dalam menentukan potensi tabir surya yang dilakukan secara in vitro yang di ukur dengan menggunakan spektrofotometer UV-VIS. SPF adalah pengukuran kuantitatif dari efektivitas formulasi tabir surya. Tabir surya adalah suatu sediaan yang mengandung senyawa yang dapat menyerap, menghamburkan atau memantulkan sinar matahari yang mengenai kulit sehingga dapat digunakan untuk melindungi fungsi dan struktur kulit manusia dari kerusakan akibat sinar surya. Nilai SPF menunjukkan berapa kali perlindungan kulit seseorang dilipatgandakan sehingga aman di bawah matahari tanpa mengalami eritema, semakin tinggi nilai SPF suatu tabir surya, maka semakin baik pula aktivitas ${ }^{4}$.

Sampel ekatrak etanol akar kalakai yang digunakan dilarutkan dalam $5 \mathrm{~mL}$ etanol $70 \%$ p.a, dan dibuar dengan konsentrasi yang berbeda-beda dianalisis menggunakan Spektrofotometer UV-Vis pada panjang gelombang 290-320 nm setiap interval $5 \mathrm{~nm}$. Percobaan dilakukan pada panjang gelombang UV-B ini bertujuan untuk mengukur kemampuan senyawa yang berpotensi sebagai tabir surya dalam melindungi kulit dari paparan sinar UV-B. UV-B memiliki energy yang dapat menembus lapisan paling luar kulit (epidermis) yang efeknya dapat terlihat langsung yaitu berupa eritema (Rai \& Srinivas,2007). Hasil perhitungan SPF dari ekstrak etanol akar kalakai dapat dilihat pada tabel 4. Berikut.

Tabel 4. Hasil Nilai SPF Ekstrak Etanol dan Air Akar Kalakai

\begin{tabular}{|c|c|c|c|}
\hline Sampel & $\begin{array}{l}\text { Konsentr } \\
\text { asi (ppm) }\end{array}$ & $\begin{array}{l}\text { Nilai } \\
\text { SPF }\end{array}$ & $\begin{array}{c}\text { Kategori } \\
\text { Daya } \\
\text { Proteksi } \\
\text { Sinar UV } \\
\text { (WHO, 2003)* }\end{array}$ \\
\hline \multirow{7}{*}{$\begin{array}{l}\text { Ekstrak } \\
\text { Etanol } \\
\text { Akar } \\
\text { Kalakai }\end{array}$} & 50 & 1,60 & Lemah \\
\hline & 100 & 3,40 & Sedang \\
\hline & 150 & 5,68 & Sedang \\
\hline & 200 & 7,13 & Kuat \\
\hline & 250 & 9,67 & Sangat Kuat \\
\hline & 300 & 11,90 & Ekstrim \\
\hline & 350 & 14,10 & Ekstrim \\
\hline
\end{tabular}

*) $0-2$ = Lemah; 3-5 = Sedang; 6-7 = Kuat; 8-10 = Sangat Kuat; $>11=$ Ekstrim

Hasil penelitian ini di lihat dari hasil absorbansi memiliki nilai SPF berturutturut sebesar 1, 3, 5, 7, 9, 11, dan 14. Dari data tersebut maka dapat dikelompokkan tingkat kemampuan indek ultravioletnya berdasarkan nilai SPF menurut WHO 2003. Berdasarkan hasil yang diperoleh dapat diketahui ekstrak etanol akar kalakai dengan konsetrasi 50 ppm diperoleh nilai SPF 1 yang berada dalam rentang 1-2 
sehingga memiliki tingkat kemampuan proteksi lemah. Ekstrak etanol akar kalakai degan konsentrasi 100 ppm, 150 ppm, 200 ppm diperoleh nilai SPF berturut-turut 3 , 5, dan 7 berada dalam rentang 3-7 termasuk memiliki tingkat kemampuan proteksi sedang sampai kuat. Sedangkan Ekstrak etanol akar kalakai dengan konsentrasi 250 ppm, 300 ppm, dan 350 ppm diperoleh nilai SPF berturutturut 9,11 , dan 14 berada dalam rentang 8- $\geq 11$ sehingga termasuk memiliki tingkat kemampuan proteksi sangat kuat sampai ekstrim yang artinya mempunyai perlindungan yang lebih/ekstrim. Pada hasil penelitian ini nilai SPF pada ekstrak etanol akar kalakai memiliki kemampuan tabir surya ekstrim.

\section{KESIMPULAN}

Kesimpulan yang dapat diperoleh dari penelitian hasil nilai SPF ekstrak etanol akar kalakai ini adalah pada konsentrasi 300 ppm, dan 350 ppm diperoleh nilai SPF berturut-turut 11, dan 14 berada dalam rentang $\geq 11$ sehingga termasuk memiliki tingkat kemampuan ekstrim yang artinya mempunyai perlindungan yang ekstrim/lebih.

\section{DAFTAR PUSTAKA}

1. World Health Organization. 2003. Sun Protection A Primary Teaching Resource.

2. Hassan, I., Dorjay, K. Sami, A. dan Anwar, P. 2013. Suncreens and Antioxidant as Photo-Protective Measures: An Update. Our Dermatol Online. 4(3): 369-374.
3. Adawiyah, R. 2018. Penetapan Parameter Standardisasi Spesifik Fenol Total dan Uji Aktivitas Tabir Surya (Sun Protector Agent) Ekstrak Etanol dan Air Pada Akar Kalakai (Stenochlaena palutris Bedd). Laporan Penelitian. Universitas MuhammadiyahPalangkaraya. Palangka Raya.

4. Anggara, R. 2015. Aktivitas Antioksidan Dan Tabir Surya Fraksi n-Butanol Kulit Bangkal (Nauclea subdita) Secara In Vitro. Skripsi. Universitas Lambung Mangkurat. Banjar Baru.

5. Wiweka, A. P., dan Zulkarnain, A, K., 2015., Uji Spf In Vitro Dan Sifat Fisik Beberapa Produk Tabir Surya Yang Beredar Di Pasaran., Majalah Farmaseutik, Vol. 11 No. 1., Fakultas Farmasi UGM, Yogyakarta.

6. Jamshidi, M., Shabani, E. Hashemi, Z. dan Ebrahimzadeh, M.A.. 2014. Evaluation of Three Method for The Extraction of Antioxidant from Leaf and Aerial Parts of Lythrun salicaria L. (Lythraceae). International Food Research Journal. 21 (2) : 783-788.

7. Tiwari, P., Kumar, B. Kaur, M. Kaur, G. dan Kaur, H. 2011. Phytochemical Screening and Extraction: A Review. Internationale Pharmaceutica Sciencia. 1: 98-106.

8. Adawiyah, R., dan Rizki, M., I. 2018. Aktivitas Antioksidan Ekstrak Etanol Akar Kalakai (Stenoclaena palutris Bedd) Asal Kalimantan Tengah. Jurnal Pharmascience.5 (01):71-77

9. Rai, R. dan Srinivas, C. R. 2007. Photoprotection. Indian Journal Dermatology, Venereology, and Leprology. 73(2): 73-79.

10. Pratiwi, R.,Budiman, S. dan Hadisoebroto, G. 2016. Penetapan Kadar Nilai Spf (Sun Protection Factor) Dengan Menggunakan Spektrofotometri Uv-Vis Pada Krim Pencerah Wajah Yang Mengandung Tabir Surya Yang Beredar Di Kota Bandung. Prosiding Seminar Nasional Kimia UNJANI-HKI 2016.

11. Zakiah. 2015. Aktivitas Antioksidan Dan Tabir Surya Fraksi Etil Asetat Kulit Batang Bangkal (Nauclea subdita) Secara In Vitro. 